\title{
Competence of a Spray Passive Down-draft Evaporative Cooling (PDEC) System for Space Cooling
}

\author{
Daeho Kang ${ }^{1}$, Richard K. Strand ${ }^{2}$ \\ ${ }^{1}$ New York City College of Technology, City University of New York, Brooklyn, NY, USA \\ ${ }^{2}$ University of Illinois at Urbana-Champaign, Urbana, IL, USA
}

\begin{abstract}
A spray PDEC system has been relatively less considered than other passive cooling strategies as one of the viable low-energy solutions in the cooling of buildings while having a great potential in energy savings. This study is intended to evaluate the capability of a spray PDEC system for space cooling. It comprises four simulation scenarios to see the system response and influence of indoor thermal environment when a spray PDEC system is adopted as a primary cooling system in two different climates. The simulation results show that a spray PDEC system causes a substantial variation in the indoor thermal environment and sensible cooling rates while substantiating significant energy savings.
\end{abstract}

\section{Introduction}

A spray PDEC system is a low-energy cooling system that consumes significantly less energy than conventional air conditioning systems. It is designed to capture the wind at the top of a tower and cool the outdoor air using water evaporation (Kang and Strand, 2013). It typically consists of a wind catcher, a tower, a water spray system, and a water pump. Significant energy saving for space cooling is the key benefit of the system since a water pump is the only energy-consuming component of the system (Bahadori et al., 2008; Fort et al., 2010; Givoni, 1994; Robinson et al., 2004). It is known to improve indoor air quality as it supplies a large amount of fresh outdoor air (Fort et al., 2010; Givoni, 1994). It could also remove pollutants in the air during the down-draft evaporative cooling process. On the other hand, a spray PDEC system is limited to a hot dry climate due to the strong climatic dependency of the evaporative cooling process (Bahadori et al., 2008; Fort et al., 2010; Givoni, 1994).

A number of studies introduced building energy simulations in order to predict the impact of a spray PDEC system (Robinson et al., 2004; Soutullo et al., 2012) since building simulation programs allow a comprehensive analysis of numerous design solutions in buildings. These studies used analytical models that heavily rely on the wet bulb depression (WBD), which is the difference between the dry and wet bulb temperature of the air. They enabled a system-level simulation for a spray PDEC system as the analytical models predicted the cooling performance of the system. They employed one-way coupling, which cannot fully embed the analytical models into the existing numerical solutions of the simulation programs. To that end, the predictions of the simulations in these studies are inaccurate.

Models have been developed and used to size a spray PDEC system (Bahadori, 2008; Ford et al., 2010; Givoni, 1994). Among those models, Givoni's model has been widely used because of its capability of humidity prediction as it includes the influence of water flow rate. However, it is unlikely accurate when climatic conditions and tower configurations differ from the ones used for the experiment. This is because the model cannot account for the variation of the mass flow rates of the inflows while including the wind speed. In addition, the impact of water droplet sizes has not been taken into account while many studies emphasized the importance of this particular parameter (Bahadori, 2008; Ford et al., 2010; Givoni, 1994). To remedy this gap, Kang and Strand (2009, 2013, 2016) completed a series of works and developed analytical models that predict the temperature and velocity of the supply air from a spray PDEC system. The analytical models embrace the influences of water droplet size. They also appropriately account for the variation of inflow mass flow rates over the wind catcher areas and the cross-sectional area of a spray PDEC tower. No study, which deals with a spray PDEC system and its applications in the literature, adequately handles these particular parameters to date. To that end, the new analytical models remarkably improve the accuracy of the predictions.

A comprehensive analysis of the impact of a spray PDEC system is critical, especially on the indoor thermal environment. The focus of the previous studies was limited to the energy saving capability of a spray PDEC system (Bahadori et al., 2008; Fort et al., 2010; Givoni, 1994, Robinson et al., 2004). The building applications for evaporative cooling have been introduced to reduce energy consumption for space cooling. The typical operational conditions of such evaporative cooling applications for buildings are to achieve the maximum WBD under the given local climatic conditions (Bahadori et al., 2008; Fort et al., 2010; Givoni, 1994; Robinson et al., 2004; Soutullo et al., 2011). A spray PDEC system is also not as responsive to the variable cooling load as a conventional air-conditioning system, due to a strong climatic dependency. A few studies investigated the indoor thermal environment through field measurements in a building conditioned by a PDEC application and postoccupancy evaluation studies (Yaghoubi et al., 1991; Shiano-Phan and Ford, 2008). Shiano-Phan and Ford 
(2008) surveyed the satisfaction of the thermal environment in spaces where a direct evaporative cooling application conditions. In general, much of the responses from the occupants in two buildings were satisfactory while those in the other two buildings, a school building and a federal court building, ranged from 2 to 4 among seven scales. These results indicated that a direct evaporative cooling application may substantially affect the indoor thermal environment and thus the productivity of the occupants, depending on the purpose of spaces. The impact of the cool humid supply air, which a spray PDEC system discharges, on the indoor thermal environment should be comprehensively understood so that some adverse effects of a spray PDEC system can be mitigated.

This study focuses on whether a spray PDEC system can maintain a comfortable thermal environment in a smallscale building space as the energy saving capability has been proven by many studies. It searches the capability of a spray PDEC system for verifying to what extent it functions as a primary cooling system not only in a hot dry climate, which an evaporative cooling system is best suited for a comfort cooling but also in a different climate. It employs the U.S. Department of Energy (DOE) reference primary school building in that a school building is suitable to introduce a spray PDEC system. It uses a modified EnergyPlus program in which new analytical models were implemented. It sets four simulation scenarios: two base scenarios that simulate the original reference building model in two climates and two PDEC scenarios that replace the original cooling systems in the original with spray PDEEC systems in the two climates. It predicts the indoor thermal environment and energy performance. It analyzes the results of the simulations to see to what extent a spray PDEC system serves as a primary cooling system.

\section{Methods}

\section{Climates}

A series of simulations were designed to see whether a spray PDEC system properly condition building spaces. The city of Yuma, AZ, USA was chosen to reflect the characteristics of a hot-dry climate as a greater temperature reduction during the down-draft evaporative cooling process is attainable, which is the reason why a spray PDEC system is commonly considered. The capability of a spray PDEC system in the other climates should also be investigated so as to see whether it can be adopted in a wide range of climates the cooling of buildings. The city of Sacramento, CA, USA was chosen to represent a warm moderate climate. ANSI/ASHRAE Standard 90.1 classifies the city of Yuma as hot-dry (2B) and the city of Sacramento as warm-dry (3B).

A representative summer day from each climate was selected that would be ideal for the operation of a spray PDEC system. The time series of the TMY3 weather data for the two climates were reviewed and one summer day that represents the characteristics of each climate was chosen. Figure 1 shows the variations in the dry- and wetbulb temperatures, as well as the wind speed on the representative summer day in the two climates. The variation in the WBDs in the city of Yuma (HD) is relatively stable throughout the occupied hours. The outdoor temperatures stay above $35^{\circ} \mathrm{C}$ during most of the occupied hours. The maximum and minimum WBDs are approximately $19.6^{\circ} \mathrm{C}$ and $10.5^{\circ} \mathrm{C}$, respectively. The peak outdoor air temperature in the city of Sacramento (MO) is approximately $36.5^{\circ} \mathrm{C}$ and the daily temperature variations are more significant. The maximum and minimum WBDs in Sacramento are approximately $11.3^{\circ} \mathrm{C}$ and $2.8^{\circ} \mathrm{C}$, respectively. The daily variations in the wind speed in the two climates are similar during the occupied hours. The peak wind speeds on the selected summer day in the two climates are approximately $7.0 \mathrm{~m} / \mathrm{s}$ in Sacramento and $6.0 \mathrm{~m} / \mathrm{s}$ in Yuma. The wind speed in both climates steadily increases throughout the day, which results in an increase of air flow rate during afternoon hours.

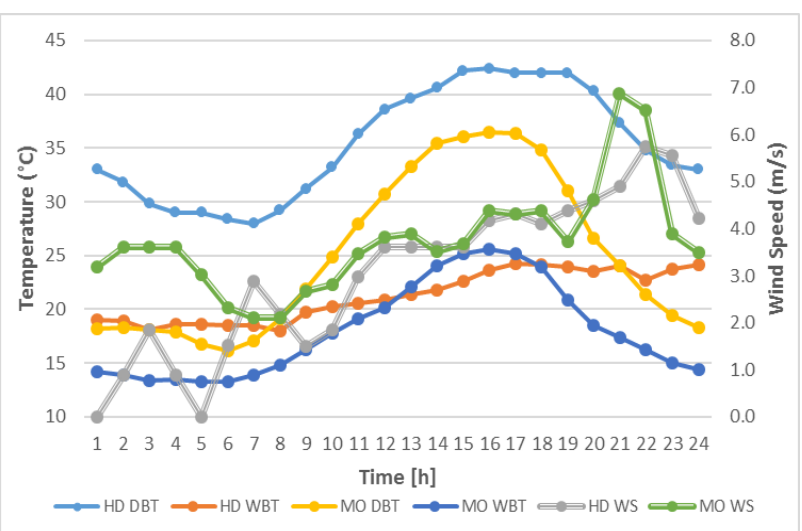

DBT: dry bulb temperature; WBT: wet bulb temperature; WS: wind speed; HD: hot dry climate; MO: moderate climate

Figure 1: Weather conditions on a representative summer day in two climates.

\section{Building}

A school building is suitable to apply a spray PDEC system for space cooling. It typically includes a number of different space types. The frequency of occupants within the building is also high. These features of a school building involve a significant variation in space cooling loads. A spray PDEC system would be responsive to such variation as the evaporative cooling process is immediate. In addition, a spray PDEC system conditions the air with no substantial energy use since it only requires the operation of a pump to supply water.

This study uses one of the U.S. DOE commercial reference building models (Torcellini et al., 2011). It uses the reference primary school building that is one story Eshaped building. The floor area of the building is $6,871 \mathrm{~m}^{2}$ and the window-to-wall ratio of the outside walls that are exposed to the outdoor environment is 0.35 . It comprises 25 thermal zones and a number of different space types. The majority of the thermal zones is classrooms. The other space types include an office, an auditorium, a kitchen, and a gymnasium. A multi-zone single duct VAV with reheat system serves most of the spaces. Packaged single zone air conditioning (PSZ-AC) units serve largescale spaces such as the auditorium, gymnasium, and kitchen. The reference primary school building model 
applies an economizer with differential dry bulb temperature control per ASHRAE Standard 90.1-2004. The indoor setpoint temperature during the occupied hours from $6 \mathrm{AM}$ to $6 \mathrm{PM}$ is $24^{\circ} \mathrm{C}$. The reference building model also sets a $3^{\circ} \mathrm{C}$ increment during the setback hours from $6 \mathrm{PM}$ to $6 \mathrm{AM}$. The U.S. DOE reference primary school building model characterizes the design conditions by ASHRAE Standard 90.1-2004 and 62-1999.

\section{System operation}

Figure 2 shows the physical phenomena taking place during the down-draft evaporative cooling process within a spray PDEC system. The outdoor air flows through a wind catcher at the very top of the system. Finer water particles created by a water spray system below the wind catcher evaporates into the inflows. The evaporative cooling process requires heats from the inflows to change the phase of the water particles from the liquid to vapor, causing a temperature drop and a humidity increase of the inflows. The conditioned air is then discharged through bottom openings to remove heats from the air in the conditioned space.

The simulations predict the properties of the supply air such as a temperature $(T)$, a mass flow rate $(\dot{m})$, a humidity ratio $(\omega)$ and an evaporation rate $(\dot{Q})$ as shown in Figure 2 and assume the supply air is immediately mixed with the air and natural air flows such as infiltration and ventilation in the conditioned space. The thermal environment in the conditioned space is determined at each zone time step if no conventional air-conditioning system is available. The computational schemes of the simulation program such as energy and moisture balances can be found in the EnergyPlus Engineering Reference. Kang and Strand (2018) also presented the detailed simulation inputs and approaches for the U.S. DOE reference building used in this study.

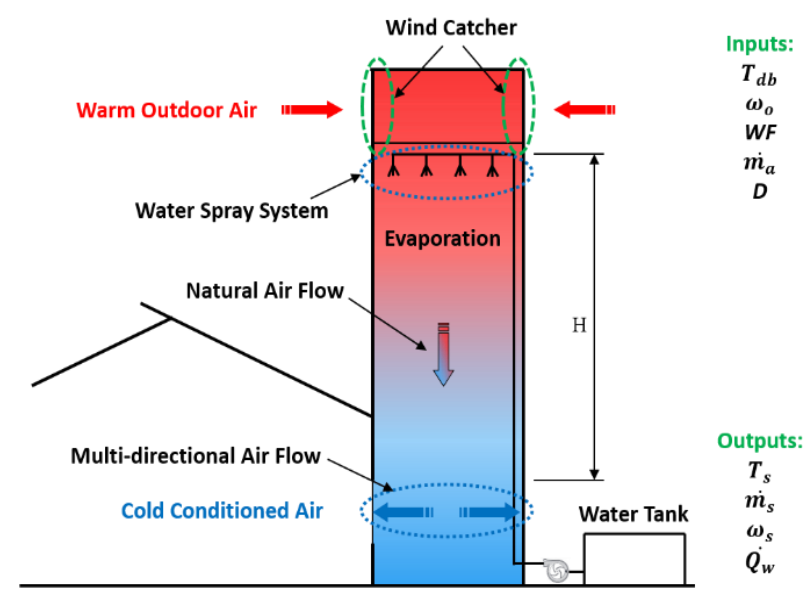

Figure 2: Schematic of a spray PDEC system and environmental variables.

Adapted from Kang and Strand, 2018

\section{Simulation description}

This study comprises four simulation scenarios. Two base simulations run the original reference building model in each climate. The other two PDEC simulations run a modified reference building model in the two climates. The PDEC scenarios replace the conventional air- conditioning systems in the original reference building model with spray PDEC systems. All the other features of the modified reference building model remained the same as the original reference building model. Due to the similarity of the simulation results in the 25 thermal zones and the constraint of the length of the paper, the study presents the results of the simulations for only one representative classroom on the west side wing in the primary school building.

This study completed a sensible design process to specify the simulation inputs. It ran preliminary simulations in order to properly size a spray PDEC system for individual space types. The preliminary simulations also evaluated whether a spray PDEC system properly reflects the operational characteristics, which are typically found in the literature (Bahadoria et al., 2008; Ford et al., 2010; Givoni, 1994; Robinson et al., 2004). Typical operating conditions for a spray PDEC system include a finer water droplet, a constant water supply, a large volume of supply water, and a high tower. These characteristics allow a spray PDEC system to attain the greatest WBD as it supplies a large amount of water and the water evaporates for a longer time.

The first round of the preliminary simulations solely applied these typical operating conditions. The results of the simulations showed some adverse impacts on the indoor thermal environment. Some adjustments were made to reduce such adverse effects, rather than applying only typical operating conditions for the simulations. It is important to note that this design process was needed to avoid an over- or under-estimation of energy savings and potential adverse impacts on the indoor thermal environment.

The simulation sets a number of inputs to define the operating conditions of the spray PDEC systems. It applies a constant water flow rate of $2001 / \mathrm{h}$ and a fixed water droplet size of $30 \mu \mathrm{m}$, which would be the most energy efficient one (Kang and Strand, 2016). It also includes system on-off controls, depending on the climatic conditions and zone air conditions. It assumes a system-off if outdoor air temperatures are lower than the minimum of $28^{\circ} \mathrm{C}$ and the relative humidity of the air is greater than the maximum of $40 \%$. In Yuma, a minimum supply air temperature of $20^{\circ} \mathrm{C}$ was used to avoid a consistent overcooling trend in the morning, which was observed in the preliminary simulations. The supply air temperature was set to be the minimum if the calculated supply air temperature is below the minimum. In Sacramento, the simulation applies no minimum in the supply air temperature since the wet-bulb temperature is lower than the minimum supply air temperature of $20^{\circ} \mathrm{C}$ for most of the occupied hours.

Climatic differences between the two climates were taken into account. The simulations include two inputs that can characterize the climatic differences. The operational conditions may vary as the performance of a spray PDEC system heavily depends on the climatic conditions. The simulations use a different input value for the last two input parameters: Minimum outdoor air temperature and 
Maximum relative humidity. The input values in the parentheses characterize the outdoor air conditions in the city of Sacramento (MO). In Sacramento, the spray PDEC systems started when outdoor air temperatures exceed $26^{\circ} \mathrm{C}$ and the relative humidity of the air is below $50 \%$.

The simulation estimates a thermal comfort index for occupants. The EnergyPlus program includes a number of models for the prediction of thermal comfort. The models use an energy balance to a person. They comprise a set of environmental variables and physiological variables in order to predict thermal comfort indexes. They divide thermal sensations of occupants into seven or nine scales. Each model handles heat transfer from the human body and the criteria for thermal sensation in a different way. Among those models, the simulations select the Fanger's thermal comfort model, which is widely used in the scientific community. The Predicted Mean Vote (PMV) index will be evaluated. The prediction of the PMV index in a thermal zone is important to see how the cool humid supply air from a spray PDEC system affects the indoor thermal environment.

Table 1: Simulation inputs for the PDEC scenarios.

\begin{tabular}{|c|c|}
\hline Input Parameters & Values \\
\hline Water flow rate $[1 / \mathrm{h}]$ & 200 \\
Effective tower height $[\mathrm{m}]$ & 5 \\
Water loss $[\%]$ & 5 \\
Air flow loss $[\%]$ & 5 \\
Rated pump power consumption $[\mathrm{W}]$ & 150 \\
Area of wind catcher $\left[\mathrm{m}^{2}\right]$ & 6.25 \\
Tower cross-sectional area $\left[\mathrm{m}^{2}\right]$ & 16 \\
Diameter of water droplet $[\mu \mathrm{m}]$ & 30 \\
Minimum supply air temperature $\left[{ }^{\circ} \mathrm{C}\right]$ & 20 \\
Minimum outdoor air temperature $\left[{ }^{\circ} \mathrm{C}\right]$ & $28(26)$ \\
Maximum relative humidity $[\%]$ & $40(50)$ \\
\hline
\end{tabular}

\section{Results}

\section{Supply air condition}

Figure 3 illustrates the time series of the supply air conditions from a spray PDEC system in the two PDEC scenarios. In the hot-dry climate Yuma, the supply air temperatures in the early morning were set to be the minimum supply air temperature of $20^{\circ} \mathrm{C}$ as the supply air was saturated and the wet bulb temperature dropped below the minimum. In a warm dry climate Sacramento, the time series of the supply air was duplicated with that of the wet bulb temperature, which means the supply air was saturated throughout the operating hours during the down-draft evaporative cooling process.

A noticeable trend found in the results of the simulation in the PDEC scenario in Yuma was that the supply air temperatures remained above the indoor setpoint temperature of $24^{\circ} \mathrm{C}$ after $3 \mathrm{PM}$. The differences between the supply air temperature and the setpoint temperature during these afternoon hours ranged from approximately $0.6^{\circ} \mathrm{C}$ to $1.5^{\circ} \mathrm{C}$ and the WBDs ranged from $16.8^{\circ} \mathrm{C}$ to $19.6^{\circ} \mathrm{C}$. The outdoor air temperatures remained above $40^{\circ} \mathrm{C}$ during this period. The spray PDEC systems may increase the cooling load as the warmer supply air potentially add heats to the classroom, depending on the zone air temperature, internal heat sources, and the magnitude of heat storage effect by the solar radiation.

The variations in the relative humidity of the supply air remained at a very high level in both climates as shown in Figure 3. The relative humidity of the supply air significantly increased as soon as the spray PDEC systems operated and remained above $80 \%$ during the operating hours in Yuma. In Sacramento, it stayed at the highest level as the supply air was saturated during the entire operating hours. In Yuma, the constant water flow rate of 2001/h led the saturation of the supply air when the outdoor air temperature was approximately below $40^{\circ} \mathrm{C}$ and the WBD was less than approximately $18^{\circ} \mathrm{C}$. When the outdoor air temperature was greater than $40^{\circ} \mathrm{C}$, the maximum WBD that could result in the saturation of the supply air was likely approximately $16^{\circ} \mathrm{C}$. The saturation of the supply air appeared throughout the occupied hours in Sacramento where the maximum WBD was approximately $10.5{ }^{\circ} \mathrm{C}$. The humid supply air likely affects the indoor humidity level while the significance of the impact varies with the volume of the supply air and the humidity level of the air in the classroom.

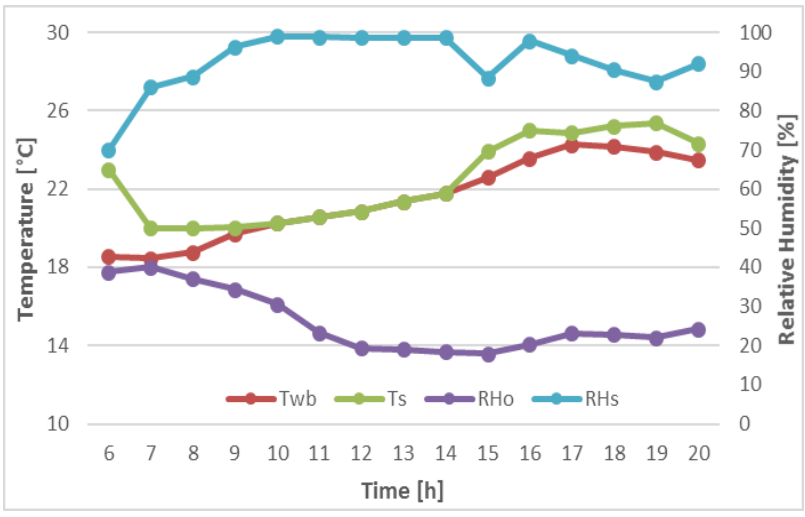

a) Yuma

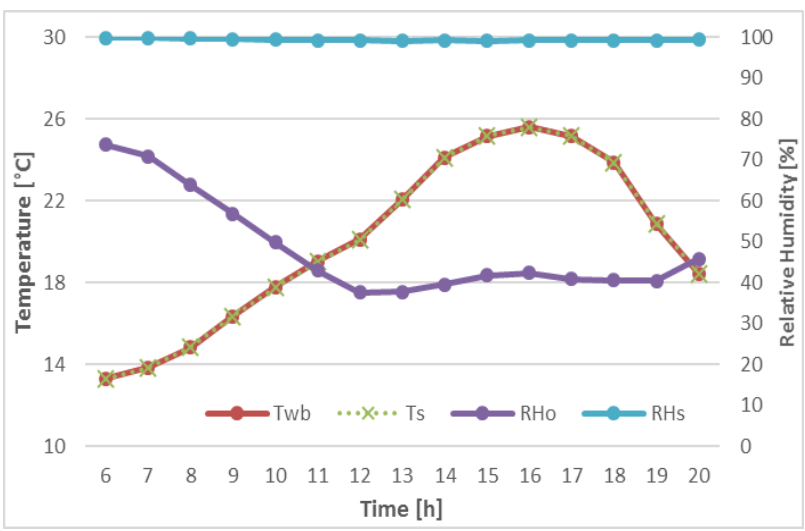

b) Sacramento

$T_{w b}$ : wet bulb temperature; $T_{s}$ : supply air temperature; $R H_{o}$ : outdoor relative humidity; $R H_{s}$ : supply air relative humidity

Figure 3: Variations in the supply air temperature in the representative classroom in the PDEC scenarios.

\section{Sensible cooling rate}

Spray PDEC systems generally overcooled the spaces when they operated as shown in Table 2. In Yuma, the sensible cooling rates provided by the spray PDEC 
systems were short in meeting the cooling loads for the first two hours. As the cooling loads started to increase, the spray PDEC systems provided cooling $12 \%$ to $98 \%$ more than the cooling loads required to meet the setpoint temperature in the classroom. The spray PDEC systems were turned off for the very first and last hours of the scheduled operation, due to the climatic conditions. In Sacramento, the spray PDEC systems operated 3 hours less than Yuma. The spray PDEC systems also provided $17 \%$ to $77 \%$ more cooling than the space cooling loads. This trend in sensible cooling rates demonstrated that the system responses of the spray PDEC system to the space cooling loads in both climates were not stable as much as conventional cooling systems.

Table 2: Sensible cooling rates in the representative classroom in the four simulation scenarios.

\begin{tabular}{|c|c|c|c|c|c|c|}
\hline \multirow{2}{*}{$\begin{array}{c}\text { Time } \\
(\mathbf{h})\end{array}$} & \multicolumn{3}{|c|}{ Yuma } & \multicolumn{3}{c|}{ Sacramento } \\
\cline { 2 - 7 } & $\begin{array}{c}\text { Base } \\
(\mathbf{P D E C}\end{array}$ & $\begin{array}{c}\text { Diff. } \\
(\mathbf{\%})\end{array}$ & $\begin{array}{c}\text { Base } \\
(\mathbf{W})\end{array}$ & $\begin{array}{c}\text { PDEC } \\
(\mathbf{W})\end{array}$ & $\begin{array}{c}\text { Diff. } \\
(\boldsymbol{\%})\end{array}$ \\
\hline 6 & 2719 & 0 & -100 & 2392 & 0 & -100 \\
\hline 7 & 2477 & 2078 & -16 & 2135 & 0 & -100 \\
\hline 8 & 2589 & 2286 & -12 & 2327 & 0 & -100 \\
\hline 9 & 2672 & 2666 & 0 & 2422 & 0 & -100 \\
\hline 10 & 2773 & 3512 & 27 & 2532 & 2406 & -5 \\
\hline 11 & 2916 & 4266 & 46 & 2656 & 3099 & 17 \\
\hline 12 & 3424 & 4217 & 23 & 2800 & 3668 & 31 \\
\hline 13 & 3826 & 5575 & 46 & 2954 & 4243 & 44 \\
\hline 14 & 4200 & 5136 & 22 & 3436 & 5588 & 63 \\
\hline 15 & 4893 & 6139 & 25 & 4529 & 6509 & 44 \\
\hline 16 & 5855 & 7149 & 22 & 5514 & 7024 & 27 \\
\hline 17 & 5728 & 6430 & 12 & 5584 & 6702 & 20 \\
\hline 18 & 3405 & 6290 & 85 & 3464 & 6115 & 77 \\
\hline 19 & 3546 & 7032 & 98 & 3409 & 5049 & 48 \\
\hline 20 & 3368 & 0 & -100 & 3120 & 0 & -100 \\
\hline
\end{tabular}

\section{Mean air temperature}

An overcooling of the space on the west side of a building in the morning is typical. An increment of heat gains by solar radiation on the east side of the building derives a rise of cooling loads while the west side gains no direct solar radiation. In addition, the operation of the airconditioning systems returns to the normal from the setback. As a result, the cooling loads in a building rises significantly in the early morning while heat gains by internal heat sources and solar radiation are the lowest of the day. Figure 4 illustrates that the base scenarios showed notable variations in the indoor air temperature in the morning, due to the typical trend in the building.

A definite trend found in the PDEC scenarios is that the spray PDEC systems overcooled the classroom for more than half of the occupied hours. As the WBDs are lower during this particular period of the day, the supply air temperatures dropped to the minimum of $20^{\circ} \mathrm{C}$ in Yuma and the operation of the spray PDEC systems delayed for the first four operating hours in Sacramento. The indoor mean air temperatures varied significantly throughout the occupied hours in both climates. In comparison with the base cases, the magnitude of the overcooling trend was much stronger and lasted for a longer time in the PDEC scenarios. The spray PDEC systems in both climates hardly met the indoor setpoint temperature of $24^{\circ} \mathrm{C}$ throughout the occupied hours. The indoor setpoint temperature was met for only 2 hours in Sacramento and for 6 hours in Yuma. In general, the variations in the wet bulb temperature were essential when the rate of water supply is high, especially in the warm humid climate Sacramento.

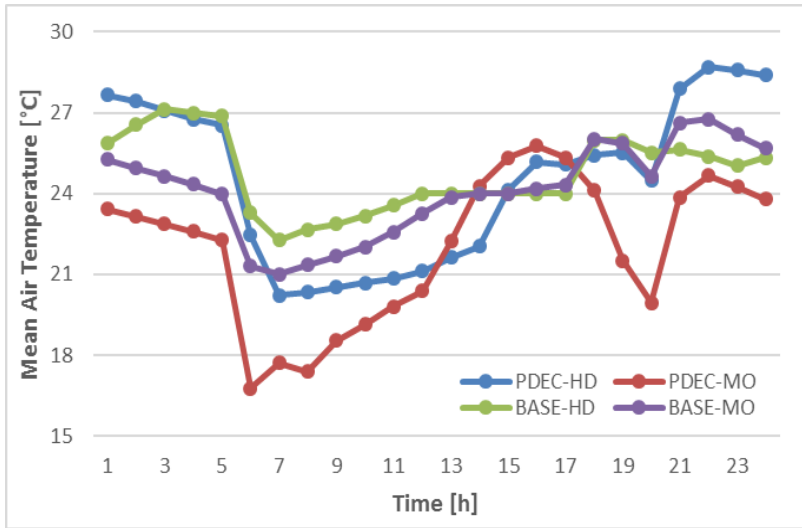

Figure 4: Variations in indoor mean air temperature in the representative classroom.

\section{Relative humidity}

Figure 5 shows the variations in relative humidity in the representative classroom in the four simulation scenarios. The variations in the two base scenarios were fairly stable within a very narrow band during most of the occupied hours. A high degree of variations in relative humidity was found in the PDEC scenarios. The difference in the relative humidity between the supply air and the outdoor air ranged from $31 \%$ to $79.6 \%$ in Yuma and from $26 \%$ to $61 \%$ in Sacramento, respectively. As the spray PDEC systems discharged the saturated supply air in the morning, the peak in the relative humidity of the zone air appeared as $64.7 \%$ at 9 AM in Yuma. The indoor relative humidity remained below $60 \%$ for most of the occupied hours, except for some morning hours. In Sacrament, the peak in the indoor relative humidity was found to be $78 \%$ at $4 \mathrm{PM}$ as the supply air was saturated throughout the day and the supply air flow rate increased during afternoon hours due to the increase of wind speed.

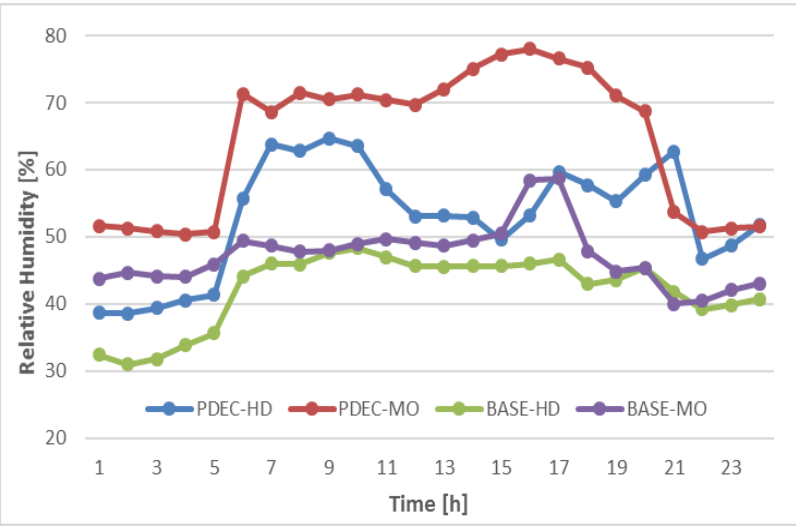

Figure 5: Variations in indoor relative humidity of the air in the representative classroom.

ANSI/ASHRAE 62.1-2016 recommends that the relative humidity in occupied spaces are limited at or below $65 \%$. 
The indoor relative humidity in Sacramento stayed above the recommended value for all the occupied hours. In contrast, the indoor relative humidity in Yuma remained below the recommended value for the entire occupied hours. The thermal comfort of the occupants is closely related to the variations in the indoor relative humidity along with other factors such as air movement, operative temperature, clothing, and activity level. The results indicated that the PMV values in Sacramento would vary more than those in Yuma and base scenarios.

\section{Thermal comfort}

The cool humid supply air prompted a significant variation in the Predicted Mean Vote (PMV) values as shown in Figure 6. ASHRAE Standard 55 - 2013 recommends an acceptable PMV range for thermal neutrality in a thermal zone as \pm 0.5 . Figure 5 displays that the definite overcooling trend in all scenarios influenced the thermal comfort of the occupants in the classroom in the morning. The PMV values in the base scenarios fell below the lower recommended value of -0.5 for a number of morning hours and then returned to the recommended range for the rest of the day, except for one or two afternoon hours. In the PDEC scenarios, the PMV values consistently varied with time. The PMV values in the PDEC scenarios fell into the recommended range only for a few hours of the day. The PMV values in Yuma remained near or above the upper recommended value during the afternoon hours since the spray PDEC systems discharged warmer air. In addition to the overcooling trend, significant variations in the indoor thermal environment stimulated such significant variations in the PMV values throughout the day.

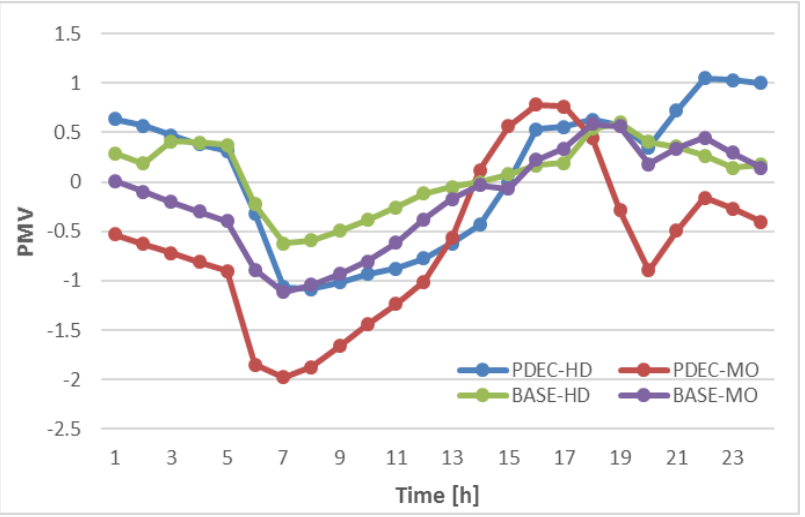

Figure 6: Variations in the Fanger PMV value in the representative classroom.

\section{Energy consumption}

Table 3 summarizes energy consumption in the four simulation scenarios. As described in the Introduction section, many studies have proven the energy saving capability of a spray PDEC system. The results of the simulations also estimated that the spray PDEC systems required a small fraction of the electricity for space cooling that the mechanical air-conditioning systems in the base scenarios consumed. The operation of the spray PDEC systems in Yuma required approximately 3.6\% of the electricity in the baas scenario. As expected, the degree of the total energy saving in Yuma is greater than
Sacramento since a greater WBD is attainable. The reduction rate of the space cooling energy in Sacramento was estimated approximately $93.4 \%$.

It is noted that the energy saving capability of a spray PDEC system in a real building differ from the predictions of the simulations in this study. The operation of a spray PDEC system in a real building is not as simple as the simulations predicted. As for the accurate predictions, the simulations should include all potential factors that may affect the energy performance in buildings. The magnitude of the cooling energy reduction would be different when the operation of a spray PDEC system requires the aids of other equipment in order to form wellmixed air flows in a space. Although the predictions of the energy reduction rates should be referred to an indicator, it is true that a spray PDEC system reduces a profuse amount of energy consumption.

Table 3: Itemized building electricity consumptions in the four simulation scenarios.

\begin{tabular}{|l|r|r|r|r|}
\hline \multirow{2}{*}{ Meters } & \multicolumn{2}{|c|}{ Yuma (HD) } & \multicolumn{2}{c|}{ Sacramento (MO) } \\
\cline { 2 - 5 } & PDEC & \multicolumn{1}{c|}{ Base } & \multicolumn{1}{c|}{ PDEC } & \multicolumn{1}{c|}{ Base } \\
\hline Cooling [MJ] & 258.7 & 7100.8 & 264.0 & 3994.6 \\
\hline Facility [MJ] & 5774.9 & 13529.4 & 5774.9 & 10324.2 \\
\hline Fans [MJ] & 0 & 683.8 & 0 & 614.0 \\
\hline
\end{tabular}

\section{Discussion}

This study employs a simulation-based method to analyze the impact of the cool humid air that a spray PDEC system discharges to the thermal zones in a primary school building, particularly on the indoor thermal environment. It fully coupled the most accurate analytical models that were validated against experimental data (Kang and Strand 2016) with the existing heat balance algorithm in EnergyPlus program that has been extensively validated (Henninger and Witte, 2015). The predictions of the performance of the spray PDEC system, the indoor thermal environment in the thermal zones, and the energy performance in the primary school building may differ from the measured data in a real building, depending on many other parameters that have not been comprehensively considered in the simulations. While the predictions of the simulations can demonstrate the implications of energy performance in buildings that a spray PDEC system serves, an experiment in an occupied space is essential to accurately evaluate various impacts of a spray PDEC system.

\section{Conclusion}

This study evaluates the influences of a spray PDEC system in the cooling of a primary school building by using a modified EnergyPlus program. The simulations predicted the system response of a spray PDEC system and the indoor thermal environment in the building spaces on a summer day under two different climatic conditions. The results of the simulations substantiated that the spray PDEC systems reduced a great portion of the cooling energy required for the operation of the conventional airconditioning systems in the base scenarios. The spray PDEC systems in Sacramento also accomplished a 
comparable energy saving with that attained in Yuma. These results indicate that a spray PDEC system may be suitable for a low-energy alternative to a conventional airconditioning system in wider climatic conditions than the hot-dry climate, which a direct evaporative cooling system has been limited for years.

A spray PDEC system in the current form may not be a stand-alone cooling system in the cooling of buildings. The results of the sensible cooling rates of the spray PDEC systems showed that they are not as responsive to the cooling loads as the conventional air-conditioning systems. The spray PDEC system operated by the typical operating conditions also involved substantial variations in the indoor thermal environment. As the indoor thermal environment strongly affects the productivity of the occupants in a building, the energy saving capability may not outweigh such adverse impact. In general, the cooling performance of a spray PDEC system in the current form requires a significant advancement in order to be a standalone cooling application that can maintain a consistent thermal environment in a space where it serves.

Studies to address problems with a spray PDEC system is needed. The spray PDEC systems in Yuma applied an onoff control to maintain the minimum temperature of the supply air. Such simple control moderated the overcooling trend in the morning. The spray PDEC systems provided more cooling than the required cooling loads in the classroom. The system response to the cooling loads can be improved when the performance of the spray PDEC systems is controllable. To that end, the control of the supply air conditions is beneficial to mitigate some of the inborn problems of a spray PDEC system.

\section{References}

ANSI/ASHRAE Standard 55 (2013). Thermal Environmental Conditions for Human Occupancy.

ANSI/ASHRAE Standard 62.1 (2016). Ventilation for Acceptable Indoor Air Quality.

ANSI/ASHRAE Standard 90.1 (2016). Energy Standard for Buildings Except Low-Rise Residential Buildings.

Bahadoria, M.N., Mazidib, M. and Dehghanic, A.R. ( 2008). Experimental investigation of new designs of wind towers. Renewable Energy, 33, 2273-2281.

Ford, B., Francis, E. and Shiano-Phan, R. (2010). The Architecture and Engineering of Downdraught Cooling. PHDC Press.
Givoni, B. (1994). Passive and Low Energy Cooling of Buildings. Van Nostrand Reinhold, New York, USA.

Henninger, R.H. and Witte, M.J. (2015). EnergyPlus Testing with HVAC Equipment Component Tests. Technical Report, US Department of Energy.

Kang, D. and Strand, R.K. (2009). Simulation of passive down-draught evaporative cooling (PDEC) systems in EnergyPlus. Proceedings from BS2009: Building Simulation Conference, Glasgow, Scotland, 27-30 July, 2009.

Kang, D. and Strand, R.K. (2013). Modeling of simultaneous heat and mass transfer within passive down-draft evaporative cooling (PDEC) towers with spray in FLUENT. Energy and Buildings 62, 196209.

Kang, D. and Strand, R.K. (2016). Significance of parameters affecting the performance of a passive down-draft evaporative cooling (PDEC) tower with a spray system. Applied Energy 178, 269-280.

Kang, D. and Strand, R.K. (2018). Performance control of a spray passive down-draft evaporative cooling system. Applied Energy 222, 915-931.

Robinson, D., Lomas, K.J., Cook, M.J., and Eppel, H. (2004). Passive down-draught evaporative cooling: thermal modelling of an office building. Indoor + Built Environment 13(3), 205-221.

Schiano-Phan, R. and Ford, B. (2008). Post occupancy evaluation of non-domestic buildings using downdraught cooling: case studies in the US. Proceedings from 25th Conference on Passive and Low Energy Architecture, Dublin, Ireland, 22-24 October, 2008.

Soutullo, S, Sanjuan, C, Heras, M.R. (2012). Energy performance evaluation of an evaporative wind tower. Solar Energy 86, 1396-410.

Torcellini, P. et. al. (2011). U.S. Department of energy commercial reference building models of the national building stock. Technical Report, NREL/TP-550046861.

U.S. Department of Energy (2016). EnergyPlus Engineering Reference.

Yaghoubi, M.A., Sabzevari, A., and Golneshan, A.A. (1991). Wind towers: measurement and performance. Solar Energy 47(2), 97-106. 